\title{
The Ampakine CX546 Restores the Prepulse Inhibition and Latent Inhibition Deficits in mGluR5-Deficient Mice
}

\author{
Tatiana Lipina*,', Karin Weiss' and John Roder ${ }^{1,2}$ \\ 'Samuel Lunenfeld Research Institute, Mount Sinai Hospital, Toronto, ON, Canada; ${ }^{2}$ Program in Neuroscience, University of Toronto, Toronto, \\ ON, Canada
}

\begin{abstract}
In order to test the possible role of mGluR5 signaling in the behavioral endophenotypes of schizophrenia and other psychiatric disorders, we used genetic engineering to create mice carrying null mutations in this gene. Compared to their mGluR5 ${ }^{+/+}$littermates, mGluR5 ${ }^{-1-}$ mice have disrupted latent inhibition (LI) as measured in a thirst-motivated conditioned emotional response procedure. Administration of the positive modulator of $\alpha$-amino-3-hydroxy-5-methyl-4-isoxazole-propionic acid receptors (AMPAR), CX546, during the conditioning phase only, improved the disrupted LI in mGluR5 knockout mice and facilitated LI in control C57BL/6) mice, given extended number of conditioning trails (four conditioning stimulus-unconditioned stimulus). Prepulse inhibition (PPI) was impaired in $\mathrm{mGluR5^{-1- }}$ mice to a level that could not be disrupted further by the antagonist of N-methyl-D-aspartate receptors - MK-80I. PPI deficit of $\mathrm{mGluR5}{ }^{-1-}$ mice was effectively reversed by $\mathrm{CX} 546$, whereas aniracetam had a less pronounced effect. These data provide evidence that a potent positive AMPAR modulator can elicit antipsychotic action and represents a new approach for treatment of schizophrenia. Neuropsychopharmacology (2007) 32, 745-756. doi: I0.1038/sj.npp. I 301 I 91; published online 23 August 2006
\end{abstract}

Keywords: mGluR5 knockout mice; PPI; latent inhibition; MK-80 I; CX546; aniracetam

\section{INTRODUCTION}

In recent years, theories focusing on glutamatergic dysfunction in the etiology of schizophrenia have received much support (Olney et al, 1999; Goff and Coyle, 2001). Glutamatergic mechanisms underlying schizophrenia are of special interest given their critical role in the modulation of cognition, mood, and motor function, which are impaired in schizophrenics (Paul and Skolnick, 2003). Historically, it was found that pharmacological blockade of $N$-methyl-D-aspartate receptor (NMDAR) induced psychotic states in healthy human volunteers and exacerbated existing symptomatology in schizophrenics (Javitt and Zukin, 1991). This observation has led to the hypothesis that NMDAR hypofunction may be critically involved in the etiology and/or underlying symptoms of schizophrenia (Olney et al, 1999). Hence, facilitation of the NMDAR may represent an effective therapeutic strategy for normalization of NMDAR function in schizophrenia. Indeed, it was shown that coagonists of the NMDAR acting at the glycine-binding site have antipsychotic efficacy in animal models and in

\footnotetext{
*Correspondence: Dr T Lipina, Samuel Lunenfeld Research Institute, Mount Sinai Hospital, 600 University Avenue, Toronto, Ontario, Canada M5G IX5, Tel: + | 416586 8242, Fax: + I 4165868588 , E-mail: lipina@mshri.on.ca

Received 2 June 2006; revised 7 June 2006; accepted 7 July 2006 Online publication: 20 July 2006 at http://www.acnp.org/citations/ Npp072006060079/default.pdf
}

schizophrenics. Compounds that enhance the activity of the NMDAR, including glycine, D-serine, the partial coagonist $\mathrm{D}$-cycloserine, and glycine transporter type 1 inhibitors, reverse NMDAR antagonist-induced behavioral effects in humans and rodents (Javitt et al, 1999; Lipina et al, 2005).

Metabotropic glutamate receptors (mGluR) add to the complexity of glutamatergic neurotransmission in the brain. In the context of NMDAR-mediated neurotransmission, the mGluR5 subtype of mGluRs is of special interest. The mGluR5 binds through G-dependent or independent pathways (Heuss et al, 1999) with predominantly couple via Gq to phospholipase C. This yields diacylglycerol, which activates protein kinase $\mathrm{C}$ (PKC), and inositol-1,4,5-triphosphate, which releases intracellular $\mathrm{Ca}^{2+}$ (Conn and Pin, 1997), and this in turn can increase NMDAR-evoked responses in a variety of neuronal tissues (Doherty et al, 1997; Awad et al, 2000), indicating one potential functional link between mGluR5 and NMDAR. Indeed, administration of mGluR5 antagonist 2-methyl-6-(phenylethynyl)pyradine (MPEP) facilitated in vivo effects of NMDAR antagonists in rodents, producing anxiolytic (Spooren et al, 2000), neuroprotective (Bruno et al, 2000), and anticonvulsant (Chapman et al, 2000) effects, disrupting prepulse inhibition (PPI) (Kinney et al, 2003) and enhancing the detrimental effects of MK-801 on cognition and stereotypy (Homayoun et al, 2004). This demonstrates that mGluR5 play a major role in regulating NMDAR-dependent function. Therefore, modulation of mGluR5 may be an effective 
therapeutic strategy for manipulation of NMDAR-mediated neurotransmission in schizophrenia (Goff and Coyle, 2001). There is also evidence, indicating a role for mGluR5 itself in the psychopathology of schizophrenia. For example, the increased neuronal mGluR5 mRNA has been found in cortical pyramidal cell layers of schizophrenics (Ohnuma et al, 1998). More importantly, linkage analysis revealed that mGluR5 has been mapped to $11 \mathrm{q} 14$, closely to a translocation that segregates with schizophrenia and related psychosis in a large Scottish family (Devon et al, 2001). The creation of the mGluR5 null mutant (mGluR5 ${ }^{-1-}$ ) (Jia et al, 1998) in our lab, offered a unique possibility to investigate how the absence of mGluR5 can modulate NMDARdependent schizophrenia-related processes in vivo, with potential discovery of new approaches for schizophrenia treatments in human.

Animal models of schizophrenia represent an important preclinical tool for testing novel pharmacological compounds in the treatment of schizophrenia. PPI and latent inhibition (LI) are two important behavioral models in neuropharmacological research of schizophrenia with face, predictive, and construct validity (Geyer and Ellenbroek, 2003). PPI is a measure of sensorimotor gating and refers to the attenuation of the startle response by a weak stimulus (prepulse) appearing a short time before the startle stimulus. Deficits in PPI have been reported in schizophrenia (Swerdlow et al, 1994; Braff et al, 2001), in patients with Huntington's disease (Swerdlow et al, 1995), Tourett's syndrome (Castellanos et al, 1996), and obsessive-compulsive disorder (Swerdlow and Geyer, 1993). The mGluR5 ${ }^{-1-}$ mice exhibited robust PPI deficits found in different laboratories (Henry et al, 1999; Brody et al, 2004a, b; Kinney et al, 2003) using mice on three different background strains, based on procedures with different stimuli modalities and startle magnitudes. However, the observed PPI deficit in mGluR5 ${ }^{-1-}$ mice was resistant to the antipsychotics (Brody et al, 2004b), suggesting that these mice cannot serve as a model with predictive validity to test for typical/atypical antipsychotic drug effects and may model some other psychiatric disorder (Brody et al, 2004b).

Here, we investigated LI as another distinctive assay for schizophrenic-like endophenotypes in mGluR5 ${ }^{-1-}$ mice. LI is a well-established phenomenon reflecting an organism's ability to learn to ignore irrelevant stimuli (Gray et al, 1992). LI paradigms are usually based on between-subject design and consist of one group of subjects being preexposed (PE) to a neutral to-be-conditioning stimulus (CS), whereas another group of subjects are not pre-exposed (NPE). The CS is subsequently paired with an unconditioned stimulus (US). LI is measured by the difference to learn the CS-US association between the PE and NPE groups and consists of a retardation of learning in the $\mathrm{PE}$ group. LI has two aspects of abnormalities relevant to the positive and negative symptoms of schizophrenia (Weiner, 2003). Healthy humans or rats treated with amphetamine show the disrupted LI, which is also associated with acute stage of schizophrenia (Gray et al, 1992; Weiner et al, 1984). On the other hand, LI can persist under conditions that normally disrupt LI, and it was suggested that persistence of LI may reflect impaired set shifting, that is associated with cognitive inflexibility and negative symptoms (Weiner, 2003). Indeed, persistent LI has been shown to positively correlate with the level of negative symptoms in schizophrenics (Cohen et al, 2004) and was found in NMDAR antagonists-treated rodents (Gaisler-Salomon and Weiner, 2003; Lipina et al, 2005). The administration of mGluR5 antagonist-MPEP to rats disrupted LI based on conditioned taste aversion (Bills et al, 2005). In addition, cognitive deficits relevant to schizophrenia were observed after MPEP treatment of rats in the spontaneous alteration test of working memory (Homayoun et al, 2004), which is among the most commonly observed cognitive impairments in schizophrenia patients (Goldman-Rakic, 1994).

If mGluR5 modulates the functional state of the NMDAR, then the absence of mGluR5 in null mutant mice could cause dysfunction of NMDAR. Indeed, using electrophysiological measurements, we found that CA1 neurons from mGluR $5^{-1-}$ mice showed a complete loss of the NMDARmediated component of long-term potentiation ( $\left.\mathrm{LTP}_{\mathrm{NMDA}}\right)$, but an unchanged LTP of AMPAR-mediated component $\left(\operatorname{LTP}_{\mathrm{AMPA}}\right)$ (Jia et al, 1998). We hypothesized here that membrane depolarization via AMPAR facilitation could activate NMDAR complex as there is a link between these two receptors (Hanley and Henley, 2005) and overcome behavioral deficits of $\mathrm{mGluR} 5^{-l-}$ animals. AMPAR are heteromeric complexes composed of four subunits (GluR1, GluR2, GluR3, and GluR4), each of which has a binding pocket for the transmitter glutamate and can be expressed as flip or flop splice variant, which is regulated regionally (Black, 2005). Several distinct classes of AMPAR modulators have been reported (Kew and Kemp, 2005) such as aniracetam (1-(4-methoxybenzoyl)-2-pyrrolidinone compound); benzamide compounds - 'ampakines' (CX516, CX546, and CX614); benzothiadiazides and related IDRA and PEPA compounds, and group of biarypropylsulfonamides (LY392098, LY404187, LY395153, LY503430). Positive AMPAR modulators do not bind to the glutamate binding site, but they interact with the receptor at an allosteric site and augment function by decreasing desensitization and/or deactivation. Such compounds have been shown to facilitate AMPAR-mediated synaptic activity both in vitro and in vivo and to stimulate memory-dependent processes in animals (Black, 2005) and are currently under development for treatment of cognitive dysfunction in various neuropsychiatric disorders, including schizophrenia. The positive AMPAR modulators can exhibit distinct selectivity for individual AMPAR subunits and their splice variants in vitro, it would provide the potential for distinct in vivo profiles for the different positive AMPAR modulators (Black, 2005). CX516 when given alone was insufficient to reverse methamphetamine or MK-801-induced behavioral deficits in animals (Vanover, 1997; Johnson et al, 1999), and only potentiated the effect of antipsychotics to reduce rearing or locomotor activities in rats (Johnson et al, 1999), which is consistent with human studies (Goff et al, 2001). Other structurally related compounds were effective against methamphetamine-induced behavior (Vanover, 1997; Larson et al, 1996). In the present study, we sought to use a new genetic model to estimate whether positive AMPAR modulators might be an effective approach to rescue schizophrenia-like behavior in mGluR5 ${ }^{-7-}$ mice and, thus, might represent a new class of potential antipsychotics. Antipsychotics increase PPI in rats (Depoortere et al, 1997) or in some inbred strains of mice (Olivier et al, 2001) and 
potentiate LI in normal rats (Moser et al, 2000) or mice (Lipina et al, 2005) under conditions that do not lead to LI. Potentiation of PPI and/or LI is a robust behavioral marker of antipsychotic activity, which is obtained with a variety of typical and atypical antipsychotics differing in their in vivo and in vitro pharmacology and, hence, fulfilling the criteria for predictive validity (Geyer et al, 2001; Moser et al, 2000).

In the present experiments, we estimated whether MK801 could exacerbate the PPI deficit observed in mGluR $5^{-1-}$ mice and investigated the effects of aniracetam and CX546 as positive AMPAR modulators on PPI in mGluR5 mice. The second part of investigation focused on LI in $\mathrm{mGluR}^{-1-}$ mice. The effects of CX546 on mGluR5 $5^{-1-}$ mice PPI were more robust than that of aniracetam; hence, we focused only on CX546 effects on LI. First, we estimated at which stage of LI procedure CX546 could facilitate LI in control C57BL/6J mice under conditions, which parametrically disrupt LI, in order to show if CX546 has antipsychotic capacity detected in this model. After finding that CX546 action is the conditioning-based LI facilitation, we administered this compound to mGluR $5^{-I-}$ mice to estimate its ability to overcome LI deficit found in mutant animals. We tested both mGluR5 ${ }^{+/+}$and ${ }^{-1-}$ mice for: (1) PPI and acoustic startle response; (2) the effects of MK-801 in a wide range of doses on PPI to estimate functional state of NMDAR in vivo in knockout mice; (3) the effects of aniracetam and CX546 on PPI and acoustic startle; (4) LI as alternative animal model of schizophrenia; and (5) the capacity of CX546 to ameliorate LI deficit in mGluR5 $5^{-/-}$ mice.

\section{MATERIALS AND METHODS}

\section{Subjects}

mGluR5 mice, generated as previously described by Jia et al (1998), were backcrossed at least 10 generations to C57BL/6J at Samuel Lunenfeld Research Institute, CMHD, Toronto, Canada. mGluR5 mice were mated heterozygously and at weaning littermates of mixed genotypes were housed by sex in groups of 3-5 per cage under a 12-h light/dark cycle (lights on at 07:00) with ad libitum food (Purina mouse chow) and water. All male mice were tested at 12 weeks old in PPI and startle response and at 16 weeks of age in LI. Behavioral testing was conducted between 09:00 and 16:00 h. Mice were randomized with regard to treatment, and were only used once. Experimenters were blind to genotype, which was determined after data collection. All animal procedures were approved by the Animal Management Committee of Mount Sinai Hospital and were conducted in accordance with the requirements of the Province of Ontario Animals for Research Act 1971 and the Canadian Council on Animal Care.

\section{Prepulse Inhibition}

PPI testing was conducted in four foam-lined (sounddamping) isolation chambers (Med. Associates Inc., Startle Reflex System, St Albans, VT). Each chamber was equipped with an acoustic stimulator (ANL-925), a platform with a transducer amplifier (PHM-255A and PHM-250B), and ventilated animal holder that was situated on the top of the platform and was large enough to allow the animal adequate movement. A fan and a red light were provided inside the chamber for the comfort of the animal when inside the enclosed chamber. PPI holders were cleaned with $70 \%$ ethanol between mice. All events were recorded and controlled by Med Associates software (Startle Reflex package).

During the test, the animal was confined to the holder. Background noise was set at $65 \mathrm{~dB}$. Five types of trials were used. Pulse alone trials $(\mathrm{P})$ consisted of a single white noise burst $(120 \mathrm{~dB}, 40 \mathrm{~ms})$. The prepulse + pulse trials (PP69P, PP73P, PP81P) consisting of a prepulse of noise $(20 \mathrm{~ms}$ at 69,73 , or $81 \mathrm{~dB}$, respectively) followed $100 \mathrm{~ms}$ after prepulse onset by a startling pulse $(120 \mathrm{~dB}, 40 \mathrm{~ms})$. No-stimulus (NS) trials consisted of background noise only. Sessions were structured as follows: (1) 15-min acclimation at background noise level; (2) five P trials; (3) 10 blocks each containing all five trials (P, PP69P, PP73P, PP81P, NS) in pseudorandom order; and (4) five $\mathrm{P}$ trials. Intertrials intervals were distributed between 12 and $30 \mathrm{~s}$. The force intensity for each trial was recorded as the startle level. The percentage PPI induced by each prepulse intensity was calculated as [1-(startle amplitude on prepulse trial)/(startle amplitude on pulse alone) $] \times 100 \%$. Startle magnitude in this formula was calculated as the average response to all of the pulse alone trials, excluding the first and last blocks of five pulse alone trials.

\section{Latent Inhibition}

The LI procedure was used as previously described (Lipina et al, 2005). In particular, we used the established parameters that yielded LI in mice as well as parameters that did not yield LI, in order to be able to demonstrate facilitated LI after drug treatment.

LI was measured in three conditioning chambers (Med. Associates Inc., St Albans, VT) each enclosed in a melamine sound attenuating chamber (ENV-022 M). The interior of the chamber was white with a speaker and a switch-control light bulb (ENV-221CL) mounted on the ceiling. Ventilation fans on the backs of the chests provided air exchange and background noise $(68 \mathrm{~dB})$. The conditioning chambers had clear Plexiglas walls (ENV-307W) and removable floors consisting of either metal rods, used on pre-exposure and conditioning days or a flat piece of aluminum used on pretraining, baseline drinking, and test days, and were equipped with a bottle with a metal tip (sipper tube). On the pre-exposure and conditioning days, access to the bottle was prevented by a guillotine door.

Foot shock of $1 \mathrm{~s}$ duration and $0.37 \mathrm{~mA}$ intensity was administered via the metal rods of the grid floor wired to a shock generator (ENV-414) via a scrambler. The auditory stimulus was an 85-dB white noise (ENV-324 M). Licks were detected by a lickometer (ENV-350CM). When the mouse made a contact with the floor of the chamber and the sipper tube (metal tip on regular bottle), a computer counted that as a lick. An IBM-PC compatible computer running MED Associates software (MED-PC) and connected to the chambers via an interface package (DIG-716P1 and ANL926) controlled the administration of training and testing stimuli. All events were programmed by MED-PC software. The chambers were cleaned with $70 \%$ ethanol between sessions. 
Before the beginning of each LI experiment, mice were weighed and water was removed from the cages for $24 \mathrm{~h}$. They were then trained to drink in the experimental chamber for 5 days, 15 min per day (training period). Body weights were monitored daily throughout all behavioral testing and maintained at no lower than $80 \%$ of the initial body weight. On each daily training session, mice were acclimated to the chamber without access to the sipper tube for $5 \mathrm{~min}$ then the guillotine door was opened. Latency to the first lick and number of licks were recorded for $15 \mathrm{~min}$. The LI procedure was conducted on days 6-9 and consisted of the following stages:

Pre-exposure. The PE mice received 40 white noise presentations with an interstimulus interval of $60 \mathrm{~s}$. The NPE mice were confined to the chamber for an identical period of time without receiving the stimuli.

Conditioning. All mice received fear conditioning to the noise stimulus. In Experiments 5 and 7 two noise-shock pairings were used to produce LI and four noise-shock pairings were used in Experiment 6 to disrupt LI in order to estimate ability of CX546 to facilitate LI in control animals. Five minutes after the start of the session, a 10-s white noise was followed by a 1-s $0.37 \mathrm{~mA}$ foot shock. The noise-shock pairings were given $5 \mathrm{~min}$ apart. After the last pairing, mice were left in the experimental chamber for an additional $5 \mathrm{~min}$. Mice received $15 \mathrm{~min}$ access to water in their home cages after pre-exposure and conditioning sessions.

Lick retraining. Mice were given a 15-min drinking session as during the training period. Data of mice that failed to complete 100 licks were dropped from the analysis.

Test. Each mouse was placed in the chamber with access to the sipper tube. When the mouse completed 75 licks the noise was presented and lasted until the mouse reached lick 101. The following times were recorded: Time to first lick, time to complete licks 50-75 (before noise onset; A period), and time to complete licks 76-101 (after noise onset; B period). Degree of lick suppression was calculated as a suppression ratio $\mathrm{A} /(\mathrm{A}+\mathrm{B})$. A lower suppression score indicates a stronger suppression of drinking. LI consists of lower suppression of drinking (higher suppression ratio) in the pre-exposed compared to the non-pre-exposed mice.

\section{Drugs}

MK-801 maleate salt (Sigma, Canada) was dissolved in saline $(0.9 \% \mathrm{NaCl})$. Doses of MK-801 are expressed as salt. MK-801 doses were chosen based on the PPI literature (Lipina et al, 2005). Aniracetam (100 mg/kg, Tocris) was dissolved in $10 \%$ 2-hydroxypropyl-b-cyclodextrin. The aniracetam dose was chosen from fear conditioning studies and hippocampal learning (Smith and Wehner, 2002). CX546 (15 mg/kg; Cortex Pharmaceutical, Irvine, CA) was dissolved in a solvent containing 25\% 2-hydroxypropyl-bcyclodextrin and $75 \%$ water. Dose of CX546 was chosen based on the literature (Gainetdinov et al, 2001) and preliminary behavioral experiments (data not shown). All drugs were administered intraperitoneally in a volume
$10 \mathrm{ml} / \mathrm{kg}$ with $30 \mathrm{~min}$ as injection-testing interval. Mice tested were drug naïve and littermates were randomly assigned to drug or vehicle injections.

\section{Experimental Design}

Experiments 1-4 tested PPI and acoustic startle response in mGluR $5^{+/+}$and mGluR5 $^{-1-}$ mice and effects of MK-801 and aniracetam/CX546 to exacerbate and restore PPI deficit in $\mathrm{mGluR}^{-1-}$ mice, respectively. Experiments with MK-801 included 10 experimental groups in a $5 \times 2$ design with the main factor of drug treatment $(0,0.15,0.3,0.6$, and $0.9 \mathrm{mg} /$ $\mathrm{kg})$ and genotype (mGluR5 $5^{+/+}$; mGluR $\left.5^{-I-}\right)$. Experiments with aniracetam $(100 \mathrm{mg} / \mathrm{kg})$ included four experimental groups in a $2 \times 2$ design with the main factor of drug treatment (vehicle, aniracetam) and genotype $\left(\mathrm{mGluR} 5^{+/+}\right.$, mGluR $\left.5^{-I}\right)$. Experiment with CX546 $(15 \mathrm{mg} / \mathrm{kg})$ included four experimental groups in a $2 \times 2$ design with the main factor of drug treatment (vehicle, CX546) and genotype (mGluR5 $^{+/+}$, mGluR5 $^{-1-}$ ).

Experiment 5 investigated LI in $\mathrm{mGluR}^{+/+}$and mGluR5 $^{-1-}$ mice with 40 pre-exposure (PE) and two noise-shock pairings. It included four experimental groups in a $2 \times 2$ design with the main factor of $\operatorname{PE~}(0,40)$ and genotype (mGluR $5^{+/+}$, mGluR5 ${ }^{-/-}$).

Experiment 6 investigated at which stage of LI procedure CX546 can facilitate LI in control C57BL/6J mice under conditions, which parametrically disrupt LI (40 PE and four CS-US pairings), as the known antipsychotics elicit distinct actions when given on different LI sessions (Shadach et al, 2000; Weiner et al, 2003). If CX546 can facilitate LI in control animals and, hence, show antipsychotic capacity, it could also restore the disrupted LI, which is relevant to schizophrenia, observed in mGluR5 mutant mice. CX546 $(15 \mathrm{mg} / \mathrm{kg})$ was administered in the pre-exposure, or in the conditioning or in both sessions. The experiment included eight experimental groups in a $2 \times 2 \times 2$ design with the main factors of PE $(0,40)$, drug in pre-exposure, and drug in conditioning (vehicle-vehicle, CX546-vehicle, vehicleCX546, and CX546-CX546).

Experiment 7 estimated effects of CX546 $(15 \mathrm{mg} / \mathrm{kg})$ on LI in mGluR5 $5^{+1+}$ and mGluR5 $5^{-1-}$ mice. Drug was given only on the conditioning session, as it was found in Experiment 6 CX546 action is the conditioning-based facilitation of LI. Hence, the experiment included eight experimental groups in a $2 \times 2 \times 2$ design with the main factors of pre-exposure $(0,40)$, genotype $\left(\right.$ mGluR $^{+/+}$, mGluR $\left.5^{-/-}\right)$, and drug treatment (vehicle, CX546).

\section{Data Analysis}

Prepulse inhibition. The percentage of inhibition of startle and basic startle response was analyzed with one-way analysis of variance (ANOVA) in Experiment 1 with gene effect as a between-subject factor, and prepulse intensity as a repeated measurement factor. In addition, Pearson's correlation coefficients were calculated to assess relationships between PPI and ASR for mGluR5 mutants. Two-way ANOVA was used in Experiments 2-4 with gene and drug effects as a between-subject factors, and prepulse intensity as a repeated measurement factor. Effects of MK-801 in four doses were evaluated separately within each genotype in 
Experiment 2. Fisher's least significance difference test (LSD) was used for post hoc comparisons when ANOVAs yielded statistically significant main effects or interactions.

Latent inhibition. Suppression ratios data were analyzed by two-way or three-way ANOVAs with main factors of preexposure $(0,40)$, genotype (mGluR $5^{+/+}$, mGluR $\left.^{-/-}\right)$, drug treatment (vehicle, CX546), or drug conditions in preexposure and conditioning (vehicle-vehicle, CX546-vehicle, vehicle-CX546, and CX546-CX546). Significant main effects and interactions were followed by LSD post hoc comparisons to assess the differences between PE and NPE groups within each genotype (Experiment 5), drug conditions (Experiment 6), and differences between drug conditions within each genotype (Experiment 7).

\section{RESULTS}

Experiment 1: PPI and Acoustic Startle Response in mGluR5 $^{+l+}$ and mGluR5 ${ }^{-I-}$ Mice

Table 1 shows PPI at the three prepulse intensities in mGluR5 ${ }^{+1+}$ and mGluR5 $5^{-1-}$ mice. The results confirm previous reports (Henry et al, 1999; Brody et al, 2004a, b; Kinney et al, 2003) showing that $\mathrm{mGluR}^{-l-}$ mice exhibited lower PPI than their wild-type littermates. PPI analysis yields significant main effect of prepulse intensities $(69,73$, and $81 \mathrm{~dB})(\mathrm{F}(2,60)=3.7, p<0.05)$, genotype $(\mathrm{F}(1,30)=10.9, \quad p<0.001)$, as well as their significant interactions $(\mathrm{F}(2,60)=7.4, p<0.001)$. Post hoc analysis revealed disrupted PPI in mGluR5 ${ }^{-1-}$ mice at $69 \mathrm{~dB}$ $(p<0.05)$, at $73 \mathrm{~dB} \quad\left(p^{\prime} s<0.01\right)$, and $81 \mathrm{~dB} \quad\left(p^{\prime} s<0.001\right)$ in comparison with wild-type littermates. ANOVA revealed a main effect of genotype on startle amplitude $(\mathrm{F}(1,30)=5.38, p<0.01)$, mGluR5 $^{-1-}$ mice have a greater startle response than mGluR5 $5^{+/+}$animals as it was seen previously (Brody et al, 2004a, b). The startle response of mGluR5 ${ }^{-1-}$ mice did not correlate with PPI at all three prepulses $(r=0.2$ for $69 \mathrm{~dB} ; r=0.17$ for $73 \mathrm{~dB}$, and $r=-0.08$ for $81 \mathrm{~dB}$ ).

\section{Experiment 2: Effect of MK-801 on PPI and Startle Response in mGluR5 ${ }^{+/+}$and $\mathrm{mGluR}^{-/-}$Mice}

Prepulse inhibition. Figures $1 \mathrm{a}$ and b show effects of MK801 on PPI at three prepulse intensity levels in mGluR $5^{+/+}$ and mGluR $5^{-1-}$ mice. There was a main effect of genotype $(\mathrm{F}(1,80)=4.9, \quad p<0.05)$, drug treatment $(\mathrm{F}(4,80)=5.9$, $p<0.01)$, as well as drug $\times$ genotype interactions $(\mathrm{F}(4,80)=$ $5.0, p \leqslant 0.001)$, and genotype $\times$ prepulse intensities interactions $(\mathrm{F}(2,160)=5.8, p<0.01)$.

Analysis of MK-801 effects separately within group of mGluR5 ${ }^{+/+}$mice identified a significant main effect of drug treatment $(\mathrm{F}(4,37)=4.6, \quad p<0.01)$ and drug $\times$ prepulse intensities interactions $(\mathrm{F}(8,74)=4.1, p<0.01)$, but no effect of prepulse intensity $(\mathrm{F}(2,74)=1.3, p=0.3)$. Vehicletreated wild-type mice did not show intensity-dependent PPI in this experiment, but prepulse intensity effect was detected in the previous Experiment 1 for naïve wild-type animals as well as for vehicle-treated wild-type mice in Experiments 3 and 4 (see below), suggesting that the main source of this discrepancy was mouse behavioral variability.
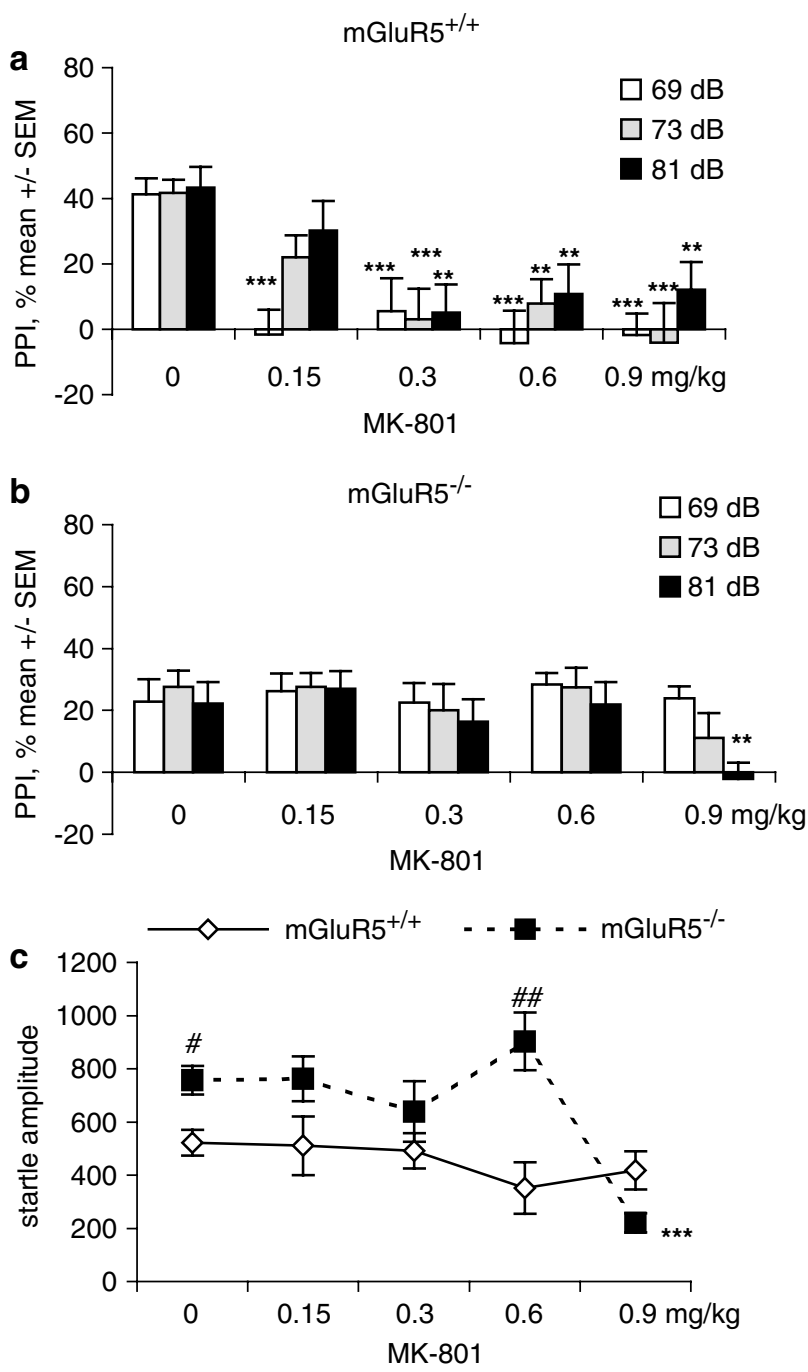

Figure I The effects of MK-80I $(0.15,0.3,0.6$ and $0.9 \mathrm{mg} / \mathrm{kg}, n=7-14$ per group) on PPI at three prepulse intensity levels in mGluR5 $5^{+/+}$(a) and mGluR5 ${ }^{-1-}$ (b) mice and acoustic startle response in both genotypes (c). *** $<<0.01$, **** $p<0.001$ - in comparison with vehicle-treated group within each genotype; ${ }^{\#}<0.05 ;{ }^{\# \#} p<0.01$ - in comparison with mGluR5 ${ }^{+/+}$mice (post hoc LSD test, ANOVA).

Table I Prepulse Inhibition at Three Prepulse Intensity Levels and Acoustic Startle Response of mGuR5 ${ }^{+/+}$and $\mathrm{mGluR5} 5^{-1-}$ Mice

\begin{tabular}{lllll}
\hline Genotype & PP69\% & PP73\% & PP8 I\% & Startle amplitude \\
\hline mGluR5 $^{+/+}(n=13)$ & $32.3 \pm 6.1$ & $38.4 \pm 5.3$ & $50.7 \pm 3.2$ & $500.8 \pm 42.0$ \\
mGluR5 $^{-1-}(n=20)$ & $12.9 \pm 6.3 *$ & $20.5 \pm 5.1 * *$ & $16.9 \pm 7.5 * * *$ & $664.3 \pm 58.4 * *$ \\
\hline
\end{tabular}

* $p<0.05, * * p<0.01, * * * * 0.001$-in comparison with $\mathrm{mGluR5^{+/+ }}$ mice (post hoc LSD test, ANOVA). 
MK-801 at all four doses disrupted PPI at three prepulse intensities in wild-type mice (Figure 1a). Post hoc analysis found that MK-801 disrupted PPI at $0.15 \mathrm{mg} / \mathrm{kg}$ at $69 \mathrm{~dB}$ $(p<0.001)$. PPI was disrupted in MK-801-treated mGluR $5^{+/+}$ mice at all three prepulse intensities at $0.3 \mathrm{mg} / \mathrm{kg}$ ( $p$ 's $<0.001$ for $69,73 \mathrm{~dB}$ and $p<0.01$ for $81 \mathrm{~dB}$ ), at $0.6 \mathrm{mg} / \mathrm{kg} \quad(p$ 's $<0.001$ for $69 \mathrm{~dB}, p$ 's $<0.01$ for $73 \mathrm{~dB}$ and $81 \mathrm{~dB})$, and at $0.9 \mathrm{mg} / \mathrm{kg}(p$ 's $<0.001$ for $69 \mathrm{~dB}, 73 \mathrm{~dB}$ and $p<0.01$ for $81 \mathrm{~dB}$ ).

Estimation of MK-801 effects on PPI of mGluR5 $5^{-1-}$ mice found a significant drug $\times$ prepulse intensities interactions $(\mathrm{F}(8,86)=4.5, p \leqslant 0.05)$, but no significant effects of drug treatment $(\mathrm{F}(4,43)=1.5, p=0.2)$ and prepulse intensity $(\mathrm{F}(2,86)=2.8, p=0.06)$ (Figure $1 \mathrm{~b}) . \mathrm{MK}-801$ had no effect on PPI of mGluR5 ${ }^{-1-}$ mice at all studied doses, except the highest dose $(0.9 \mathrm{mg} / \mathrm{kg})$ at $81 \mathrm{~dB}(p<0.01)$.

Startle. Figure 1c depicts the mean startle amplitude in the five drug conditions: vehicle, $0.15 \mathrm{mg} / \mathrm{kg}, 0.3,0.6$, and $0.9 \mathrm{mg} / \mathrm{kg}$ of MK-801 in mGluR5 mice. ANOVA revealed a significant main effect of drug treatment on startle amplitude $(\mathrm{F}(4,80)=6.3, p<0.001)$, genotype effect $(\mathrm{F}(1,80)=10.5, p<0.001)$ as well as their interactions $(\mathrm{F}(4,80)=2.4, p \leqslant 0.05)$. Post-hoc did not find significant effect of MK-801 at all doses on startle in mGluR $5^{+/+}$ animals (all $p$ 's $>0.05$ ). MK-801 did not change startle in mGluR5 ${ }^{-I-}$ mice at all doses, except $0.9 \mathrm{mg} / \mathrm{kg}(p<0.001)$.

\section{Experiments 3-4: Effects of Aniracetam and CX546 on} Impaired PPI in mGluR5 ${ }^{-1-}$ Mice

Aniracetam. Two-way ANOVA found a main effect of genotype $(\mathrm{F}(1,34)=10.8, p<0.001)$, prepulse intensities $(\mathrm{F}(2,68)=5.3, \quad p<0.01)$ and genotype $\times$ drug $\times$ prepulse intensities interactions $(\mathrm{F}(2,68)=4.3, p<0.05)$. Vehicletreated $\mathrm{mGluR} 5^{-1-}$ mice exhibited lower PPI than vehicletreated wild-type littermates $(p<0.05$ at $69 \mathrm{~dB}$ and $73 \mathrm{~dB}$; $p<0.01$ at $81 \mathrm{~dB}$; Figure 2a). Post hoc analysis revealed that aniracetam slightly facilitated PPI at $69 \mathrm{~dB}$ in mGluR $5^{+/+}$ mice $(p<0.05)$ and at $81 \mathrm{~dB}$ in $\mathrm{mGluR}^{-1-}$ mutants $(p<0.05)$. Aniracetam had no effect on startle $(\mathrm{F}(1,34)=1.0, p>0.05$; Table 2).

CX546. Two-way ANOVA revealed significant effect of drug treatment $(\mathrm{F}(1,31)=19.1, p<0.001)$, prepulse intensities $(\mathrm{F}(2,62)=2.8, p<0.05)$, as well as genotype $\times$ drug treatment interactions $(\mathrm{F}(1,31)=7.6, p<0.01)$. Post hoc analysis found that CX546-treated mGluR5 ${ }^{-1-}$ mice significantly improved PPI in prepulse intensity-dependent manner compared with vehicle-treated mGluR5 ${ }^{-1-}$ animals $(p<0.01$ at $69 \mathrm{~dB}, p<0.001$ at 73 and $81 \mathrm{~dB}$, respectively; Figure $2 \mathrm{~b}$ ). CX546 had no effect on mGluR $5^{+/+}$littermates (all $p$ 's $>0.05$ ) or startle amplitude $(\mathrm{F}(1,31)=3.1, p>0.05$; Table 2$)$.

Experiment 5: LI with $40 \mathrm{PE}$ and 2 CS-US in mGluR5 ${ }^{+/+}$ and mGluR5 ${ }^{-1-}$ Mice

There was no difference in A period between genotypes (all $p$ 's $>0.05$, overall A period $=6.5 \mathrm{~s}$ ). Figure 3 depicts the mean suppression ratios of the PE and NPE groups in both genotypes of mGluR5 mice. There was a significant main effect of pre-exposure $(\mathrm{F}(1,56)=49.5, p<0.001)$,
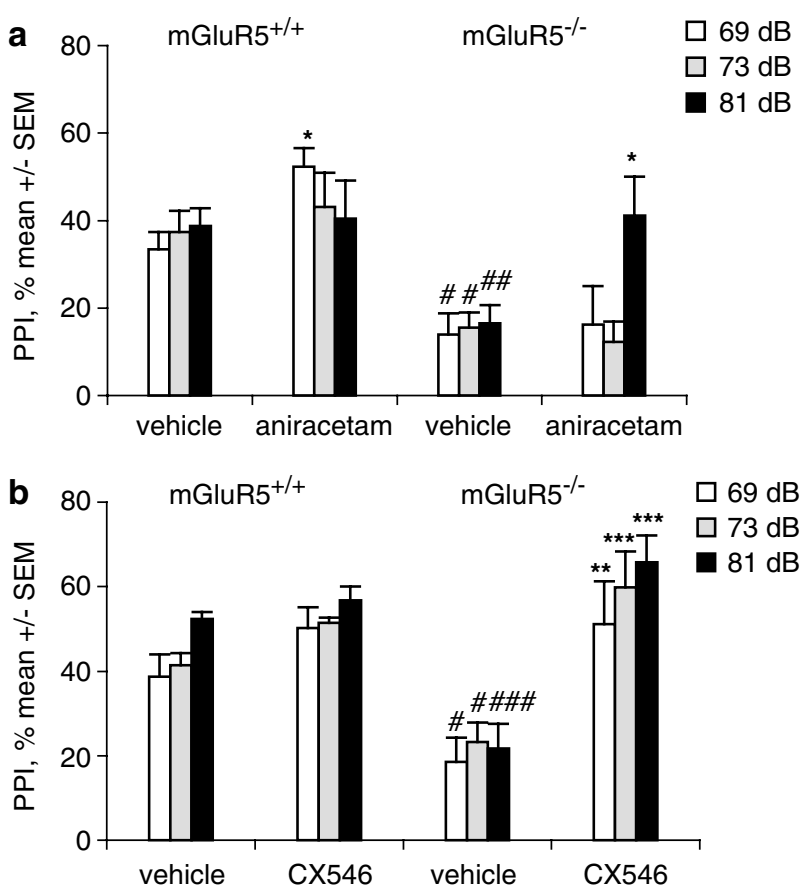

Figure 2 CX546 (15 mg/ $/ \mathrm{kg})$ (b), but not aniracetam $(100 \mathrm{mg} / \mathrm{kg})$ (a) improved PPI at all three prepulse intensity levels in $\mathrm{mGluR5^{-1- }}$ mice. ${ }^{*} p<0.05, * * p<0.01$, **** $p<0.001$ - in comparison with vehicle-treated group within each genotype; $\# p<0.05,{ }^{*} p<0.01, \quad \# \# p<0.001$ - in comparison with vehicle-treated mGluR5 ${ }^{+1+}$ mice (post hoc LSD test, ANOVA).

Table 2 Startle Magnitude of $\mathrm{mGluR} 5^{+/+}$and $\mathrm{mGluR5} 5^{-/-}$Mice Administered Vehicle, Aniracetam ( $100 \mathrm{mg} / \mathrm{kg})$, and CX546 $(15 \mathrm{mg} / \mathrm{kg})$

\begin{tabular}{lcll}
\hline & Dose $(\mathbf{m g} / \mathbf{k g})$ & \multicolumn{1}{c}{ mGluR5 $^{+/+}$} & \multicolumn{1}{c}{ mGluR5 $^{-l-}$} \\
\hline Aniracetam & 0 & $774.5 \pm 47.6(n=10)$ & $850.6 \pm 46.3 *(n=12)$ \\
& 100 & $737.2 \pm 47.3(n=8)$ & $798.6 \pm 67.6(n=7)$ \\
CX546 & 0 & $758.3 \pm 53.2(n=8)$ & $900.3 \pm 51.7 *(n=8)$ \\
& 15 & $817.4 \pm 40.2(n=8)$ & $904.9 \pm 85.4(n=10)$ \\
\hline
\end{tabular}

* $p<0.05$-in comparison with mGluR5 $5^{+/+}$mice (post hoc LSD test, ANOVA)

genotype $(\mathrm{F}(1,56)=9.9, p<0.001)$, and their interactions $(\mathrm{F}(1,56)=7.5, p<0.001)$. Post hoc comparisons found existence of LI in mGluR5 $5^{+/+}(p<0.001)$, that is, there was a significant difference between PE and NPE groups within wild-type animals. However, there was no LI in mGluR $5^{-1-}$ mice $(p>0.05)$. LI was disrupted in mGluR5 ${ }^{-1-}$ mice owing to the significant decrease of PE score compared to wild-type mice $(p<0.001)$, that is, their ability to ignore irrelevant CS, but there was no difference in suppression scores of NPE animals between genotypes $(p>0.05)$.

Experiment 6: Effect of CX546 on LI with $40 \mathrm{PE}$ and Four CS-US in C57BL/6J-Administered in PE, in Conditioning, and in PE + Conditioning Sessions

The eight experimental groups did not differ in their times to consume water between 50 and 75 licks (all p's $>0.05$; 


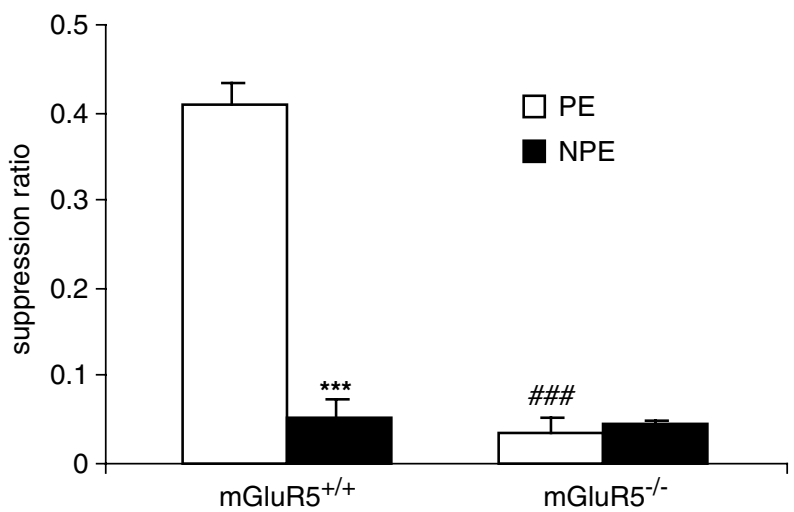

Figure $3 \mathrm{mGluR5} 5^{-1-}$ mice showed disrupted LI. Mean suppression ratios of the pre-exposed (PE) and non-pre-exposed (NPE) mGluR5 ${ }^{+/+}$ and $\mathrm{mGluR5} 5^{-1-}$ mice conditioned with two CS-US ( $n=10-16$ per group) following 40 nonreinforced CS pre-exposures. $* * * * 2<0.001-N P E$ in comparison with PE score; \#\#\# $p<0.001-P E$ mGluR5 ${ }^{-1-}$ mice in comparison with PE mGluR5 ${ }^{+1+}$ mice (post hoc LSD test, ANOVA).

overall mean A period $=7.3 \mathrm{~s}$ ). Figure 4 represent the mean suppression ratios of PE and NPE groups in four drug conditions in pre-exposure and conditioning: vehiclevehicle, CX546-vehicle, vehicle-CX546, and CX546-CX546. ANOVA revealed a main effect of pre-exposure $(\mathrm{F}(1,67)=$ $4.8, p<0.05)$, a significant main effect of CX546 in conditioning $(\mathrm{F}(1,67)=7.63, p \leqslant 0.01)$ indicating that, overall, the groups that received CX546 in conditioning were less suppressed than the groups that received vehicle in conditioning, as well as a significant pre-exposure $\times$ drug in conditioning interaction $(\mathrm{F}(1,67)=7.5, p<0.01)$, pointing that the effect of pre-exposure differed depending on whether mice were given CX546 or vehicle in conditioning, irrespective of the drug condition in pre-exposure. As can be seen in Figure 4, there was no LI in mice that received vehicle in both pre-exposure + conditioning sessions, in those mice that received CX546 in pre-exposure or in both pre-exposure + conditioning (all p's $>0.05$ ), whereas mice that received CX546 only in conditioning session exhibited LI $(p<0.01)$.

Experiment 7: Effect of CX546 Given in the Conditioning Session on LI with $40 \mathrm{PE}$ and Two CS-US in mGluR5 ${ }^{+/+}$ and mGluR5 ${ }^{-I-}$ Mice

In this experiment, we administered CX546 only on the conditioning session as we found conditioning-based CX546 action in the previous experiment. The eight experimental groups did not differ in their times to consume 50-75 licks (all $p$ 's $>0.05$; overall mean A period $=8.7 \mathrm{~s}$ ). Figure 5 represents the mean suppression ratios of mGluR $5^{+/+}$and mGluR $5^{-1-}$ mice in two drug conditions (vehicle, CX546). Multiple ANOVA revealed a main effect of pre-exposure $(\mathrm{F}(1,58)=141.5, p<0.001)$, genotype $(\mathrm{F}(1,58)=29.5, \quad p<0.001)$, drug treatment $(\mathrm{F}(1,58)=7.6, p<0.001)$ as well as their interactions $(\mathrm{F}(1,58)=24.6, p<0.001)$. ANOVA did not detect drug effect on mGluR $5^{+/+}$mice $(\mathrm{F}(1,26)=4.2, p>0.05)$, whereas there was a significant effect of drug treatment on mGluR5 ${ }^{-l-}$ mice $(\mathrm{F}(1,32)=39.5, p<0.001)$. Post hoc analysis revealed that $\mathrm{CX} 546$-treated $\mathrm{mGluR}^{-1-}$ mice

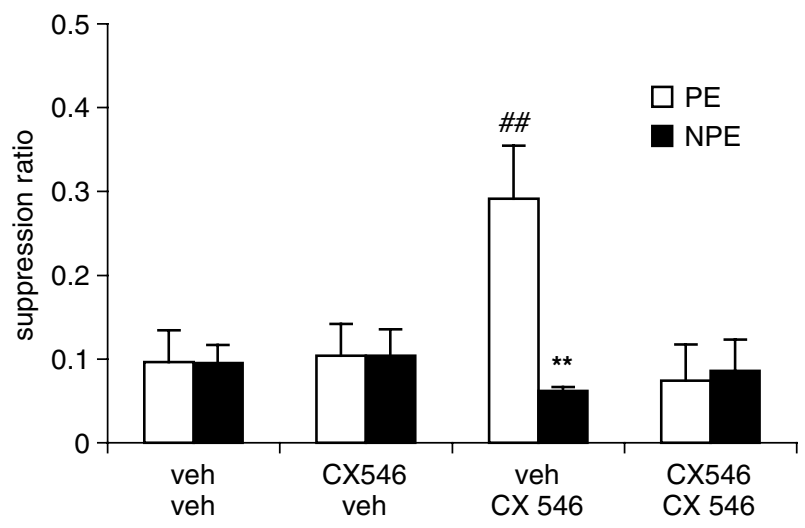

Figure 4 CX546 facilitated $\mathrm{LI}$ in control C57BL/6) mice under conditions, which parametrically disrupted LI, when given only in the conditioning session. Mean suppression ratios of the pre-exposed (PE) and non-pre-exposed (NPE) C57BL/6J mice in four drug conditions in preexposure and conditioning: vehicle-vehicle, CX546-vehicle, vehicleCX546, and CX546-CX546 ( $n=7-10$ per group). Forty noise preexposures and four CS-US pairings were used. *** $<0.01-N P E$ in comparison with PE score; ${ }^{\# \#} p<0.01$ - vehicle-CX546-treated PE mice in comparison with vehicle-vehicle-treated PE mice (post hoc LSD test, ANOVA).

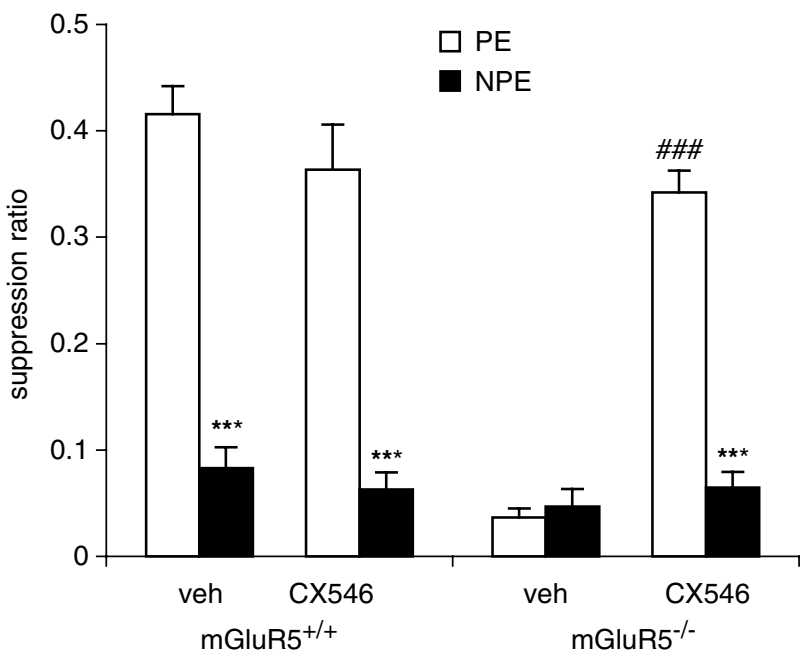

Figure 5 CX546 restored the disrupted LI of mGluR5 mutants. Mean suppression ratios of the pre-exposed (PE) and non-pre-exposed (NPE) mGluR5 ${ }^{+/+}$and $\mathrm{mGluR5}^{-1-}$ mice given vehicle or CX546 in the conditioning session ( $n=7-12$ per group). Forty noise pre-exposures and two CS-US pairings were used. **** $p<0.001$-NPE in comparison with PE score within each genotype and drug treatment; ${ }_{\# \# \#} p<0.001$ - CX546-treated PE mGluR5 ${ }^{-1-}$ mice in comparison with vehicle-treated PE mGluR5 ${ }^{-1-}$ mice (post hoc LSD test, ANOVA).

developed LI $(p<0.001)$ as well as vehicle- and CX546treated mGluR5 $5^{+/+}$mice (both $p$ 's $<0.001$ ).

\section{DISCUSSION}

Our results confirmed previous findings showing that mGluR5 $^{-l-}$ mice have a PPI deficit (Henry et al, 1999; Brody et al, 2004a, b; Kinney et al, 2003) that could not be impaired further by MK-801. We go on to show that the PPI deficit of mGluR5 $5^{-1-}$ mutants was completely restored by 
the positive AMPAR modulator, CX546, but not by aniracetam. The mGluR $5^{-1-}$ mice exhibited profoundly disrupted LI as another schizophrenia-like behavioral endophenotype, which was also restored by CX546. In an experiment with wild-type C57BL/6J mice, only acute administration of CX546 on the conditioning session was able to restore the disrupted LI in control animals given extended number of conditioning trails (four CS-US), which is a reliable behavioral indicator of a drug's antipsychotic activity. Thus, CX546 demonstrated antipsychotic capacities to restore PPI and LI deficits in mGluR5 ${ }^{-I-}$ mice and the disrupted LI in control animals with four CS-US trails.

The mGluR5 null mutant mice were resistant to administration of NMDAR antagonist, MK-801, except the highest dose, which impaired PPI further. Whereas all doses of MK801 disrupted PPI in wild-type animals. This implies a hypofunctional state of NMDAR in mice lacking mGluR5. A functional interactions between mGluR5 and NMDAR is well supported by the literature (Salter and Kalia, 2004) and our own data (Jia et al, 1998; Huang et al, 2001; Hannan et al, 2001). Indeed, several observations have shown that agonists and antagonists of mGluR5 may, respectively, attenuate and potentiate the effects of NMDAR antagonists in vivo (Kozela et al, 2003; Kinney et al, 2003; Homayoun et al, 2004). As mGluR5 antagonist administered alone could not disrupt PPI, but could enhance the effects of PCP (Kinney et al, 2003), it is possible that the PPI deficit in mGluR5 mutants might result from an interaction between NMDAR hypofunction together with missing mGluR5 complex rather than the alternative of only a parallel pathway downstream of mGluR5. The regulation of NMDAR is very complex and the present study did not dissect molecular pathways underlying NMDAR functional changes in mGluR5 ${ }^{-1-}$ mouse. Interactions between NMDAR and mGluR5 likely occur through several mechanisms, for example, interactions with PKC (Conn and Pin, 1997), intracellular Homer/Shank proteins (Ango et al, 2001; Tu et al, 1999), other signaling molecules (Husi et al, 2000), which could mediate loss of the NMDAR function caused by lack of mGluR5 (Salter and Kalia, 2004).

Based on electrophysiological data that loss of mGluR5 did not impair excitatory synaptic potential of AMPAR (Jia et al, 1998), we suggested that functional state of AMPAR in mGluR5 ${ }^{-1-}$ mutants was normal. It is possible that positive AMPAR modulators could activate NMDAR as there is a link of these two receptors (Hanley and Henley, 2005) and lead to improved behavior in mGluR $5^{-1-}$ animals. Indeed, we observed that both positive AMPAR modulators - aniracetam and CX546 - had positive effects on impaired PPI of mGluR5 mutant mice but with different efficacies. Our results are the first to demonstrate a major in vivo role of AMPAR facilitation in overcoming the glutamatergic deficit caused by genetic perturbations. There are a few pharmacological reports supporting the role of the AMPAR in PPI regulation, such as local infusion of AMPAR agonist into the core of the nucleus accumbens significantly reduced PPI in rats (Wan et al, 1995). Administration of aniracetam, a pyrrolidonic cognition-enhancing drug, only partially improved PPI in mGluR5 mutants as detected at the highest prepulse intensity, whereas benzoylpyrroliden compound - CX546, which belongs to group of 'ampakines', dramatically restored PPI. It is interesting to note that PPI deficit of $\mathrm{mGluR}^{-/-}$mice was consistently detected regardless of prepulse intensity effect; however, positive AMPAR modulator, CX546, improved PPI in prepulse intensity-dependent manner, implying that positive treatment can ameliorate the effect of intensity on sensorimotor gaiting processes. Originally aniracetam initiated development of more potent positive AMPAR modulators such as 'ampakines' that rapidly cross blood-brain barrier and facilitate synaptic transmission in the hippocampus (Granger et al, 1993; Staubli et al, 1994). Hence, known low potency and rapid metabolism of aniracetam (Lynch, 2004) can explain its mild effect on PPI deficit in mGluR5 mutants compared to the pronounced CX546 effect. However, as only single dose and postinjection time was used for aniracetam, the present results should be considered as preliminary. Additional explanation of different aniracetam and CX546 efficacies in restoring PPI impairments of mGluR5 mutants could be due to their different AMPAR subunit selectivity. Indeed, differences have been seen on AMPAR subunits and splice-variant selectivity among different AMPAR modulators (Tsuzuki et al, 1992; Partin et al, 1996; Nagarajan et al, 2001), with distinct in vivo profiles (Black, 2005). Aniracetam had more pronounced effect on GluR1 plus GluR2 heteromeric receptor than in the GluR1 homomeric receptor alone (Tsuzuki et al, 1992), whereas CX546 more effectively removed desensitization in patches containing GluR2 subunits as compared to GluR1 (Nagarajan et al, 2001). AMPAR subunits have distinct regional brain distribution (Black, 2005), which could contribute to different therapeutic profiles of different positive AMPAR modulators. However, further experiments are needed to clarify input of each AMPAR subunit in modulation of PPI expression.

Reversal of PPI deficit is a reliable index of antipsychotic activity, which was obtained with different antipsychotics (Geyer et al, 2001). mGluR5 $5^{-l-}$ mice showed resistance to such action (Brody et al, 2004b). Hence, as discussed previously by Brody with colleagues (2004b), mGluR5 mutants cannot serve 'as animal model with predicted validity to test for either typical or atypical antipsychotic drug effects'. However, the robust PPI deficit in mGluR5 mutants was restored here by positive AMPAR modulator-CX546. This implies that mGuR5 knockout mice represent a genetic mouse model with specific underlying neuronal mechanisms and offer a unique possibility to develop antipsychotic compounds with novel mechanisms of action working through the glutamatergic system. In light of recently established glutamatergic theory of schizophrenia (Olney et al, 1999; Goff and Coyle, 2001), this genetic model is very important as only a few reliable genetic mouse models of schizophrenia with perturbations in glutamatergic system exist, including for example, Grin $1^{481 \mathrm{D} / \mathrm{K} 483 \mathrm{Q}}$ mutants with decreased glycine affinity (Ballard et al, 2002), NR1 knockdown (NR1 KD) mice with $70 \%$ reduction of NR1 expression (Iwasato et al, 1997), Homer 1 mutant mice with impaired regulation of glutamate within limbicocorticostriatal structures (Szumlinski et al, 2005), proline dehydrogenase mutant mice with elevated level of proline that modulate transmission of glutamatergic synapses (Gogos et al, 1999). Interestingly clozapine also did not reverse PPI deficit observed in NR1 KD mice, which is 
similar to antipsychotics' response of $\mathrm{mGluR} 5^{-1-}$ mice. To date most of the gene-modified mice have not been validated with known antipsychotics.

We investigated LI as another schizophrenia-like behavioral endophenotype in mGluR $5^{-l-}$ mice and found the disrupted LI in mutant mice specifically owing to the inability of pre-exposed mutants to ignore CS as irrelevant stimulus, whereas non-pre-exposed mutants showed normal associative learning in response to the CS (Figure 3). This is consistent with the earlier report that mGluR5 knockout mice showed impaired contextual fear conditioning but normal fear conditioning in response to the CS ( $\mathrm{Lu}$ et al, 1997). The disrupted LI in mGluR $5^{-1-}$ mice mimics the pharmacologically disrupted LI in rats treated by mGluR5 antagonist-MPEP (Bills et al, 2005). We applied further treatment of CX546 as compound with more pronounced positive effect on the impaired PPI in mGluR5 mutants, to estimate also its ability to rescue LI deficit. LI is widely used for screening and development of new antipsychotics (Moser et al, 2000; Weiner, 2003); however, CX546 has not been tested yet in this model. Hence, we were the first to investigate whether CX546 can produce antipsychotic effects on LI in control animals. If so, CX546 could facilitate LI under conditions, which disrupt LI in control C57BL/6J mice, particularly as we previously reported, LI was disrupted in this inbred strain of mice with four conditioning trails (Lipina et al, 2005). Action of antipsychotics might depend upon the stage when drug was administered. For instance, typical and atypical antipsychotics produce LI facilitation effect when administered in the conditioning or in both conditioning and pre-exposure sessions, but not when given only in the pre-exposure (Shadach et al, 2000; Weiner et al, 2003); moreover, atypical antipsychotics in low doses can even disrupt LI when administered in the pre-exposure. Therefore, first we evaluated at which stage of LI procedure CX546 might potentiate the disrupted LI. Experiment with inbred C57BL/ 6J mice revealed that CX546 facilitation of the disrupted LI was exerted only at the conditioning stage (Figure 4), administration of CX546 in the pre-exposure and in both conditioning and pre-exposure stages did not produce any effect on LI. The LI facilitation by CX546 is similar to effects of known antipsychotics potentiated LI given in the conditioning session (Weiner et al, 1997). However, CX546 action was distinct from, for example, D2 antagonists, or typical antipsychotics (Weiner et al, 1997; Shadach et al, 2000; Moser et al, 2000) or NMDAR coagonists (Lipina et al, 2005), which facilitated LI when administered in both stages. Hence, CX546 may represent a new class of potential antipsychotics but with different mechanisms of action from conventional antipsychotics. AMPAR number and sensitivity to agonists is increased upon induction of LTP (Maren et al, 1993) as well as recruitment of silent AMPA synapses was demonstrated upon induction of LTP in electrophysiological experiments (Isaac et al, 1995). LTP is frequently suggested as a synaptic marker of associative memory in the hippocampus (Morris et al, 1990), and it has also been demonstrated in the amygdala (LeDoux, 2000). Specifically, fear conditioning is thought to occur when initially weak CS path to the amygdala becomes strengthened via LTP by being temporally paired with strong US path to the amygdala (Kim and Jung, 2006). Therefore, we suggest that induction of LTP underlying conditioning session of LI, enlarge functional capacities of AMPAR, and as a result positive modulator of AMPAR, CX546, elicited its effect only at the conditioning stage. However, it still remains to be elucidated why CX546 specifically improved only selective attention of the pre-exposed animals without any effect on associative learning of non-pre-exposed mice or why CX546 did not facilitate LI given in both sessions - pre-exposure and conditioning. It is interesting to note that comparison of our current data with previous results with NMDA coagonists (Lipina et al, 2005) suggests different mechanisms of action for NMDAR and AMPAR modulators. It is well known that the NMDAR induces neuroplasticity, whereas AMPA subtype of ionotropic glutamate receptors maintain the potentiated state (Huang and Stevens, 1998), which probably contribute to the observed differences in effects of NMDAR and AMPAR modulators on LI facilitation, but it remains to be investigated in further experiments.

After finding that CX546 action is the conditioning-based LI facilitation, we applied this compound to mGluR $5^{-1-}$ mice to estimate its capacity to overcome their LI deficit, found in procedure with 40 pre-exposure tones and two CSUS trails. Indeed, CX546 was able to restore LI deficit in mGluR5 ${ }^{-I-}$ mice without any effect on learning capacity of non-pre-exposed mice or ability of pre-exposed wild-type animals to ignore irrelevant CS.

To sum up, CX546 improved both PPI and LI deficits observed in mGluR5-deficient mice with similar efficacy, indicating on major role of AMPAR facilitation to overcome functional deficit of glutamatergic system. The effects of CX546, however, were specific only to the impaired PPI and LI behaviors observed in $\mathrm{mGluR}^{-1-}$ mice or produced in C57BL/6J mice by parametric manipulation, without any facilitation effects on normal PPI or LI processes in control animals. As effects of the drug are specific, it provides promising new possibilities in the treatment of schizophrenia, but the mechanisms of antipsychotic action of CX546 remain to be elucidated.

Although both schizophrenia-related PPI and LI behaviors were impaired and consequently improved by CX546 in mGluR5 mutants, the modulatory roles of mGluR5 and NMDAR in expression of these behavioral deficits are probably different. Pharmacologically it was shown that mGluR5 antagonists elicit different effects on PPI and LI, exacerbating effects of NMDAR antagonists on PPI without any effects of its own (Kinney et al, 2003), and disrupting LI by itself (Bills et al, 2005). As we suggested before, mGluR $5^{-I-}$ mice might also have a hypofunction of NMDAR and, hence, PPI deficit observed in mGluR5 ${ }^{-1-}$ mice is likely NMDAR- and mGluR5-dependent. The role of NMDAR in LI and associative learning has been established (Bardgett et al, 2003; Gaisler-Salomon and Weiner, 2003; Lipina et al, 2005). It is well documented that NMDAR antagonists impair or abolish associative learning at high doses (Bardgett et al, 2003). However, systemic administration of MK-801 at low dose induces abnormally persistent LI in rats (Gaisler-Salomon and Weiner, 2003) and in mice (Lipina et al, 2005), without effects on associative learning. Whereas we did not detect any impairment expected from abnormal functioning of NMDAR in mGluR5 ${ }^{-1-}$ mice in the LI paradigm (mutants 
did not demonstrate learning deficits, and did not show excessive LI), it would suggest that LI deficit in mice missing mGluR5 is likely independent from the NMDAR and hence, only mGluR5 plays a major role in the modulation of LI deficit, which is also supported by a pharmacological study with mGuR5 antagonist (Bills et al, 2005). In spite of the different inputs of mGluR5 and NMDAR in expression of PPI and LI deficits, both schizophrenia-related behavioral impairments have been compensated by CX546, implying that AMPAR facilitation could overcome both mGluR5 and NMDAR functional deficits, which is in a good agreement with an electrophysiological study (Ugolini et al, 1999).

In summary, the present results provide several general conclusions: (1) lack of mGluR5 in null mutant mice causes stable impairments in both PPI and LI paradigms relevant to schizophrenia and, hence, supporting a role of mGluR5 in pathogenesis of schizophrenia and suggesting that these mice represent an animal model for preclinical screens to detect a new class of antipsychotics; (2) absence of mGluR5 causes hypofunction of the NMDAR, supporting functional link between mGluR5 and NMDAR. PPI deficit of mGluR5 mutants is likely mGluR5-NMDAR-dependent, whereas only mGluR5 play a major role in modulation of the disrupted LI. (3) at the behavioral level, CX546, positive AMPAR modulator, restored PPI and LI deficits observed in $\mathrm{mGluR}^{-/-}$mice and facilitated LI in control animals under conditions that disrupted LI, providing evidence that CX546 can elicit antipsychotic action and represent a new focus for treatment of schizophrenia.

\section{ACKNOWLEDGEMENTS}

We thank Alexander Kraev for genotyping, Ina Weiner for advice in setting up latent inhibition in mice. TL holds a CIHR Fellowship. This work was supported by the OMHF.

\section{REFERENCES}

Ango F, Prezeu L, Muller T, Tu JC, Xiao B, Worley PF et al (2001). Agonist-independent activation of metabotropic glutamate receptors by the intracellular protein Homer. Nature 411: 962-965.

Awad H, Hubert GW, Smith Y, Levey AI, Conn PJ (2000). Activation of metabotropic glutamate receptor 5 has direct excitatory effects and potentiates NMDA receptor currents in neurons of the subthalamic nucleus. J Neurosci 20: 7871-7879.

Ballard TM, Puly-Evers M, Higgins GA, Ouagazzal AM, Mutel V, Borroni E et al (2002). Severe impairment of NMDA receptor function in mice carrying targeted point mutations in the glycine binding site results in drug-resistant nonhabituating hyperactivity. J Neurosci 22: 6713-6723.

Bardgett ME, Boeckman R, Krochmal D, Fernando H, Ahrens R, Csernansky JG (2003). NMDA receptor blockade and hippocampal neuronal loss impair fear conditioning and position habit reversal in C57BL/6J mice. Brain Res Bull 60: 131-142.

Bills C, Schachtman TR, Serfozo P, Spooren WP, Gasparini F, Simonvi A (2005). Effects of metabotropic glutamate receptor 5 on latent inhibition in conditioned taste aversion. Behav Brain Res 157: 71-78.

Black MD (2005). Therapeutic potential of positive AMPA modulators and their relationship to AMPA receptor subunits.
A review of preclinical data. Psychopharmacology (Berlin) 179 154-163.

Braff D, Geyer MA, Swerdlow NR (2001). Sensorimotor gating and schizophrenia: human and animal model studies. Arch Gen Psychiatry 47: 181-188.

Brody SA, Conquet F, Geyer MA (2004b). Effect of antipsychotic treatment on the prepulse inhibition deficit of mGluR5 knockout mice. Psychopharmacology 172: 187-195.

Brody SA, Dulawa SC, Geyer MA, Conquet F (2004a). Assessment of a prepulse inhibition deficit in a mutant mouse lacking mGlu5 receptors. Mol Psychiatry 9: 35-41.

Bruno V, Ksiazek I, Battaglia G, Lukic S, Leonhardt T, Sauer D et al (2000). Selective blockade of metabotropic glutamate receptor subtype 5 is neuroprotective. Neuropharmacology 39: 2223-2230.

Castellanos FX, Fine EJ, Kaysen D, Marsh WL, Rapport JL, Hallet M (1996). Sensorimotor gaiting in boys with Tourette's syndrome and ADHD: preliminary results. Biol Psychiatry 39: 33-41.

Chapman AG, Nanan K, Williams M, Meldrum BS (2000). Anticonvulsant activity of two metabotropic glutamate group I antagonists selective for the mGlu5 receptor: 2-methyl-6(phenylethynyl)-pyridine (MPEP), and (E)-6-methyl-2-styrylpyridine (SIB 1893). Neuropharmacology 39: 1567-1574.

Cohen E, Sereni N, Kaplan O, Weizman A, Kikinzon L, Weiner I et al (2004). The relation between latent inhibition and symptom-types in young schizophrenics. Behav Brain Res 149: $113-122$.

Conn PJ, Pin JP (1997). Pharmacology and functions of metabotropic glutamate receptors. Ann Rev pharmacol Toxicol 37: 261-281.

Depoortere R, Perrault G, Sanger DJ (1997). Some, but not all, antipsychotic drugs potentiate a low level of prepulse inhibition shown by rats of the Wistar strain. Behav Pharmacol 8: 364-372.

Devon RS, Anderson S, Teaguo PW, Muir WJ, Murray V, Pelosi AJ et al (2001). The genomic organisation of the metabotropic glutamate receptor subtype 5 gene, and its association with schizophrenia. Mol Psychiatry 6: 311-314.

Doherty AJ, Palmer MJ, Henley JM, Collingridge GL, Jane DE (1997). RS)-2-chloro-5-hydroxyphenylglycine (CHPG) activates mGluR5, but no mGluR1, receptors expressed in $\mathrm{CHO}$ cells and potentiates NMDA responses in the hippocampus. Neuropharmacology 36: 265-267.

Gainetdinov RR, Mohn AR, Bohn LM, Caron MG (2001). Glutamatergic modulation of hyperactivity in mice lacking the dopamine transporter. Proc Natl Acad Sci USA 98: 11047-11054.

Gaisler-Salomon I, Weiner I (2003). Systemic administration of MK-801 produces an abnormally persistent latent inhibition which is reversed by clozapine but not haloperidol. Psychopharmacology (Berlin) 166: 333-342.

Geyer MA, Ellenbroek B (2003). Animal behavior models of the mechanisms underlying antipsychotic atypicality. Prog Neuropsychopharmacol Biol Psychiatry 27: 1071-1079.

Geyer MA, Krebs-Thomson K, Braff DL, Swerdlow NR (2001). Pharmacological studies of prepulse inhibition models of sensorimotor gating deficits in schizophrenia: a decade in review. Psychopharmacology (Berlin) 156: 117-154.

Goff DC, Coyle JT (2001). The emerging role of glutamate in the pathophysiology and treatment of schizophrenia. Am J Psychiatry 158: 1367-1377.

Goff DC, Leahy L, Berman I, Posever T, Herz L, Leon AC et al (2001). A placebo-controlled pilot study of the AMPAkine CX516 added to clozapine in schizophrenia. J Clin Psychopharmacol 21: 484-487.

Gogos JA, Santha M, Takacs Z, Beck KD, Luine V, Lucas LR et al (1999). The gene encoding proline dehydrogenase modulates sensorimotor gating in mice. Nat Genet 21: 434-439.

Goldman-Rakic PS (1994). Working memory dysfunction in schizophrenia. J Neuropsychiatry Clin Neurosci 6: 348-357. 
Granger R, Staubli U, Davis M, Perez Y, Nilsson L, Rogers GA et al (1993). A drug that facilitates glutamatergic transmission reduces exploratory activity and improves performance in a learning-dependent task. Synapse 15: 326-329.

Gray NS, Hemsley DR, Gray JA (1992). Abolition of latent inhibition in acute, but not chronic, schizophrenics. Neurol Psychiatr Brain Res 1: 83-89.

Hanley JG, Henley JM (2005). PICK1 is a calcium-sensor for NMDA-induced AMPA receptor trafficking. EMBO J 24: 32663278.

Hannan AJ, Blakemore C, Katsnelson A, Vitalis T, Huber KM, Bear $\mathrm{M}$ et al (2001). PLC- $\beta 1$, activated via mGluRs, mediates activitydependent differentiation in cerebral cortex. Nat Neurosci 4: 282-288.

Henry SA, Dulawa SC, Conquet E, Geyer MA (1999). Sever disruption of prepulse inhibition (PPI) in mice lacking mGluR5. Soc Neurosci Abstr 25: 405-412.

Heuss C, Scanziani M, Gahwiler BH, Gerber U (1999). G-proteinindependent signalling mediated by metabotropic glutamate receptors. Nat Neurosci 2: 1070-1077.

Homayoun H, Stefani MR, Adams BW, Tamagan GD, Moghaddam B (2004). Functional interaction between NMDA and mGlu5 receptors: effects on working memory, instrumental learning, motor behaviors, and dopamine release. Neuropsychopharmacology 29: 1259-1269.

Huang Y, Lu W, Ali DW, Pelkey KA, Pitcher GM, Lu YM et al (2001). CAKbeta/Pyk2 kinase is a signaling link for induction of long-term potentiation in CA1 hippocampus. Neuron 29: 485-496.

Huang EP, Stevens CF (1998). The matter of mind: molecular control of memory. Essays Biochem 33: 165-178.

Husi H, Ward MA, Choudhary JS, Blackstock WP, Grant SG (2000). Proteomic analysis of NMDA receptor-adhesion protein signaling complexes. Nat Neurosci 3: 661-669.

Isaac JTR, Nicoll RA, Malenka RC (1995). Evidence for silent synapses: implications for the expression of LTP. Neuron 15: 427-434.

Iwasato T, Erzurumlu RS, Huerta PT, Chen DF, Sasaoka T, Ulupinar E et al (1997). NMDA receptor-dependent refinement of somatotopic maps. Neuron 19: 1201-1210.

Javitt DC, Balla A, Sershen H, Lajtha A (1999). Reversal of phencyclidine-induced effects by glycine and glycine transport inhibitors. Biol Psychiatry 45: 668-679.

Javitt DC, Zukin SR (1991). Mechanisms of phencyclidine (PCP)$\mathrm{N}$-methyl-D-asparate (NMDA) receptor interaction: implications for schizophrenia. In: Tamminga CA, Schulz SC (eds). Neuropsychological Study of Schizophrenia in Schizophrenia Research: Advances in Neuropsychiatry and Psychopharmacology. Raven Press: New York. pp 13-20.

Jia Z, Lu Y, Henderson J, Taverna F, Romano C, Abramow-Newerly $\mathrm{W}$ et al (1998). Selective abolition of the NMDA component of long-term potentiation in mice lacking mGluR5. Learn Mem 5: 331-343.

Johnson SA, Luu NT, Herbst TA, Knapp R, Lutz D, Arai A et al (1999). Synergistic interactions between AMPAkines and antipsychotic drugs. J Pharmacol Exp Ther 289: 392-397.

Kew JNC, Kemp JA (2005). Ionotropic and metabotropic glutamate receptor structure and pharmacology. Psychopharmacology 179: $4-29$.

Kim JJ, Jung MW (2006). Neural circuits and mechanisms involved in Pavlovian fear conditioning: a critical review. Neurosci Biobehav Rev 30: 188-202.

Kinney GG, Burno M, Campbell UC, Hernandez LM, Rodriguez D, Bristol LJ et al (2003). Metabotropic glutamate subtype 5 receptors modulate locomotor activity and sensorimotor gating in rodents. J Pharmacol Exp Ther 306: 116-123.

Kozela E, Pilc A, Popik P (2003). Inhibitory effects of MPEP, an mGluR5 antagonist, and memantine, an $\mathrm{N}$-methyl-D-asparate receptor antagonist, on morphine antinociceptive tolerance in mice. Psychopharmacology 165: 245-251.

Larson J, Qach CN, LeDuc BQ, Nguyen A, Rogers GA, Lynch G (1996). Effects of an AMPA receptor modulator on methamphetamine-induced hyperactivity in rats. Brain Res 738: 353-356.

LeDoux JE (2000). Emotion circuits in the brain. Annu Rev Neurosci 23: 155-184.

Lipina T, Labrie V, Weiner I, Roder J (2005). Modulators of the glycine site on NMDA receptors, D-serine and ALX 5407, display similar beneficial effects to clozapine in mouse models of schizophrenia. Psychopharmacology 179: 54-67.

Lu YM, Jia Z, Janus C, Henderson JT, Gerlai R, Wojtowicz JM et al (1997). Mice lacking metabotropic glutamate receptor 5 show impaired learning and reduced CA1 long-term potentiation (LTP) but normal CA3 LTP. J Neurosci 17: 5196-5205.

Lynch G (2004). AMPA receptor modulators as cognitive enhancers. Curr Opin Pharmacol 4: 4-11.

Maren S, Tocco G, Standley S, Baudry M, Thompson RF (1993). Postsynaptic factors in the expression of long-term potentiation (LTP): increased glutamate receptor binding following LTP induction in vivo. Proc Natl Acad Sci USA 90: 9654-9658.

Morris RG, Davis S, Butcher SP (1990). Hippocampal synaptic plasticity and NMDA receptors: a role in information storage? Philos Trans R Soc Lond B Biol Sci 329: 187-204.

Moser PC, Hitchcock JM, Lister S, Moran PM (2000). The pharmacology of latent inhibition as an animal model of schizophrenia. Brain Res Rev 33: 275-307.

Nagarajan N, Quast C, Boxall AR, Shahid M, Rosenmund C (2001). Mechanisms and impact of allosteric AMPA receptor modulation by the AMPAkine CX546. Neuropharmacology 31: 650-663.

Ohnuma T, Augood SJ, Arai H, McKenna PJ, Ernson PC (1998). Expression of the human excitatory amino acid transporter 2 and metabotropic glutamate receptors 3 and 5 in the prefrontal cortex from normal individuals and patients with schizophrenia. Mol Brain Res 56: 207-217.

Olney JW, Newcomer JW, Farber NB (1999). NMDA receptor hypofunction model of schizophrenia. J Psychiatry Res 33: 523-533.

Olivier B, Leahy C, Mullen T, Paylor R, Groppi VE, Sarnyai Z et al (2001). The DBA/2J strain and prepulse inhibition of startle: a model system to test antipsychotics? Psychopharmacology (Berlin) 156: 284-290.

Partin KM, Fleck MF, Mayer ML (1996). AMPA receptor flip/flop mutants affecting deactivation, desensitization and modulation by cyclothiazide, aniracetam and thiocyanate. J Neurosci 16: 6634-6647.

Paul IA, Skolnick P (2003). Glutamate and depression clinical and preclinical studies. Ann NY Acad Sci 1003: 250-272.

Salter MW, Kalia LV (2004). Src kinases: a hub for NMDA receptor regulation. Nat Rev Neurosci 5: 317-328.

Shadach E, Gaisler I, Schiller D, Weiner I. (2000). The latent inhibition model dissociates between clozapine, haloperidol, and ritanserin. Neuropsychopharmacology 23: 151-161.

Smith AM, Wehner JM (2002). Aniracetam improves contextual fear conditioning and increases hippocampal $\gamma$-PKC activation in DBA/2J mice. Hippocampus 12: 76-85.

Spooren WP, Vassout A, Nejt HC, Kuhn R, Gasparini F, Roux S et al (2000). Anxiolytic-like effects of the prototypical metabotropic glutamate receptor 5 antagonist 2-methyl-6(phenylethynyl)pyridine in rodents. J Pharmacol Exp Ther 295: 1267-1275.

Staubli U, Rogers G, Lynch G (1994). Facilitation of glutamate receptors enhances memory. Proc Natl Acad Sci USA 91: 777-781.

Swerdlow NR, Braff DL, Taaid N, Geyer MA (1994). Assessing the validity of an animal model of deficient sensorimotor gaiting in schizophrenia patients. Arch Gen Psychiatry 51: 139-154. 
Swerdlow NR, Geyer MA (1993). Clozapine and haloperidol in an animal-model of sensoriomotor gaiting deficits in schizophrenia. Pharmacol Biochem Behav 44: 741-744.

Swerdlow NR, Paulsen J, Braff DL, Butters N, Geyer MA, Swerdlow MR (1995). Impaired prepulse inhibition of acoustic and tactile startle response in patients with Huntington's disease. J Neurol Neurosurg Psychiatry 58: 192-200.

Szumlinski KK, Lominac KD, Kleschen MJ, Oleson EB, Dehoff MH, Schwarz MK et al (2005). Behavioral and neurochemical phenotyping of Homer1 mutant mice: possible relevance to schizophrenia. Genes Brain Behav 4: 273-278.

Tsuzuki K, Takeuchi T, Ozawa S (1992). Agonist- and subunitdependent potentiation of glutamate receptors by a nootropic drug aniracetam. Mol Brain Res 16: 105-110.

Tu JC, Xiao B, Naisbitt S, Yuan JP, Petralia RS, Brakemn P et al (1999). Coupling of mGluR/Homer and PSD-95 complexes by the Shank family of postsynaptic density proteins. Neuron 23: 583-592.

Ugolini A, Corsi M, Bordi F (1999). Potentiation of NMDA and AMPA responses by the specific mGluR $_{5}$ agonist CHPG in spinal cord motoneurons. Neuropharm 38: 1569-1576.
Vanover KE (1997). Effects of AMPA receptor positive modulators on amphetamine- and dizocilpine-induced locomotion. Eur J Pharmacol 332: 115-119.

Wan FJ, Geyer MA, Swerdlow NR (1995). Presynaptic dopamineglutamate interactions in the nucleus accumbens regulate sensorimotor gating. Psychopharmacology (Berlin) 120: 433-441.

Weiner I (2003). The 'two-headed' latent inhibition model of schizophrenia: modeling positive and negative symptoms and their treatment. Psychopharmacology (Berlin) 169: 257-297.

Weiner I, Lubow RE, Feldon J (1984). Abolition of the expression but not the acquisition of latent inhibition by chronic amphetamine in rats. Psychopharmacology (Berlin) 83: 194-199.

Weiner I, Schiller D, Gaisler-Salomon I (2003). Disruption and potentiation of latent inhibition by risperidone: the latent inhibition model of atypical antipsychotic action. Neuropsychopharmacology 28: 499-509.

Weiner I, Shadach E, Barkai R, Feldon J (1997). Haloperidol- and clozapine-induced enhancement of latent inhibition with extended conditioning: implications for the mechanisms of action of neuroleptic drugs. Neuropsychopharmacology 16: $42-50$. 